\title{
Mortality in Immatures of the Floodwater Mosquito Ochlerotatus albifasciatus (Diptera: Culicidae) and Effects of Parasitism by Strelkovimermis spiculatus (Nematoda: Mermithidae) in Buenos Aires Province, Argentina
}

\author{
Raúl Ernesto Campos ${ }^{+}$, Victoria Elena Sy
}

Instituto de Limnología “Dr. Raúl A. Ringuelet”, Universidad Nacional de La Plata, cc 712, (1900) La Plata, Argentina

Life tables were constructed for six cohorts of immature stages of the floodwater mosquito Ochlerotatus albifasciatus (Macquart) in a park in Buenos Aires, highlighting the mortality attributable to the parasitic nematode, Strelkovimermis spiculatus Poinar \& Camino. Two cohorts were selected to compare parasite incidence in all mosquito stages when low and high parasitism occurred. Development time of Oc. albifasciatus from first instar to adult was 7.7-10 days in the spring, 6 days in the summer, and 10.9-21.9 days in the fall. Survival was estimated as 0-1.4\% in the spring, 2\% in the summer and $0.2-4.4 \%$ in the fall. The highest " $K$ " value (Killing power) occurred during a fall cohort when prevalence of the parasite was $86.9 \%$, and the lowest in a spring cohort. Parasitism occurred during all seasons, but S. spiculatus persisted to adult only in the summer and fall, when adult mosquitoes developed from parasitized third and fourth instars larvae. The abundance of S. spiculatus differed between old and young larvae only when parasite prevalence was the highest. Although pupae and adults of Oc. albifasciatus were parasitized, no pupal mortality attributable to parasitism was recorded. The proportion of parasitized adults ranged from $14.2 \%$ and $5.7 \%$ in the two cohorts compared. Pupal wet weight and adult wing lengths did not differ between parasitized and unparasitized individuals.

Key words: Ochlerotatus albifasciatus - Aedes albifasciatus - mortality - floodwater mosquito - Strelkovimermis spiculatus parasitism - Buenos Aires - Argentina

Ochlerotatus (Ochlerotatus) albifasciatus (Macquart) is a floodwater mosquito widely distributed in Argentina (Darsie \& Mitchell 1985), incriminated in 1982 as a vector of Western Equine Encephalitis (WEE) (Mitchell et al. 1987). The bite of Oc. albifasciatus may also cause allergic reactions in persons who are hypersensitive to salivary allergens. These have been recently isolated and identified from this mosquito (Docena et al. 1999).

In the wet and temperate climate of Buenos Aires Province, Oc. albifasciatus occurs from spring to fall with occasional hatches in winter if temperature increases (Maciá et al. 1995). Temperature and rainfall were cited as the main factors that determine the fluctuation in the abundance of Oc. albifasciatus (Maciá et al. 1995, Fontanarrosa et al. 2000, García \& Micieli 2000, Gleiser et al. 2000). However, it is known that mortality of the immature stages plays an important role in adult survival and abundance, as was reported by Andis and Meek (1985) for Psorophora columbiae.

García et al. (1994) and Maciá et al. (1995) studied the natural enemies of immature Oc. albifasciatus in temper-

\footnotetext{
This work, was supported by a Grant (PIP no. 700/98) from Consejo Nacional de Investigaciones Científicas y Técnicas (Conicet), Argentina. This paper is a scientific contribution no. 734 of the Instituto de Limnología "Dr. R. A. Ringuelet".

+Corresponding author. Fax: +54-11-4275.7799. E-mail: rcampos@ilpla.edu.ar

Received 23 July 2002

Accepted 22 January 2003
}

ate Argentina. Microsporidans, fungi and nematodes were frequently encountered being the mermithid Strelkovimermis spiculatus Poinar \& Camino the main cause of epizootic.

S. spiculatus was discovered in 1986 from immature Oc. albifasciatus in Buenos Aires (Poinar \& Camino 1986). At present, the parasite is known from the immature stages of five species of Ochlerotatus (Lynch-Arribalzaga) and Culex (L.) mosquitoes (García \& Camino 1990, García et al. 1994). Two studies described the seasonal prevalence of S. spiculatus, one in Cx. pipiens L. (Campos et al. 1993) and the other in Oc. albifasciatus and Oc. crinifer (Theobald) (Maciá et al. 1995). Recently Micieli and García (1999) described the seasonal prevalence and sex ratio of $S$. spiculatus in eight cohorts of Oc. albifasciatus studied over 19 months, and estimated the abundance of pre-parasites in pools.

Poinar and Camino (1986), suggested that this nematode shows promise as an agent for biological control of mosquitoes in Argentina. Camino and Reboredo (1994, 1996) studied the life cycle and mass production of $S$. spiculatus in the laboratory. However, discrepancies between the life histories of this nematode in the laboratory and the field suggest the need for more research on parasite-host dynamics in epizootic situations before using this nematode for mosquito control.

We developed our research with this intention, and to estimate the mortality, survival, and developmental rates of $O c$. albifasciatus immatures in parasitized and unparasitized populations using life table methods appropriate for integrate mosquito control (Reisen \& Siddiqui 1979). Although life budgets have been formulated for 
the immature stage of many mosquito species in nature (Service 1993), to date no life tables of parasitized $O c$. albifasciatus are available.

The objectives of this study were to examine seasonal patterns of immature mortality and survival of $O c$. albifasciatus, in six cohorts followed through the spring, summer and fall. In two cohorts, the mortality attributable to $S$. spiculatus was quantified and the parasitism of adult mosquitoes characterized.

\section{MATERIALS AND METHODS}

Study site - The study area is located in Argentina in the Pampeana biogeographic province ( 30 to $\left.39^{\circ} \mathrm{S}\right)$ of the Neotropical region. Vegetation consists of Graminaceae pasture coexisting with a few shrub species. The climate is temperate (annual average from 13 to $17^{\circ} \mathrm{C}$ ) with yearround rainfall (Cabrera \& Willink 1980). The study site was located in the Pereyra Iraola Park (Buenos Aires Province) in a woodland situated near an urban area. The park was created in the 19th century with native and exotic trees. Some parcels of the park are cultivated by agriculturists and floriculturists, and others are used for cattle raising. The larval habitats of Oc. albifasciatus selected for the study consisted of four transient floodwater pools situated in open land. Pool surface areas were not estimated because the edges were not clearly discerned. The pool bottoms consisted of a layer of leaf litter and debris and water depth after a rainfall period was variable $(0.10$ to $0.50 \mathrm{~m}$ ). In the summer, the pools became dry within 6 days but in fall and spring they remained waterlogged for 10 to 25 days.

Larval mortality and survival curves - From October 2000 through June 2001 immature Oc. albifasciatus were collected every day after pool inundation. One hundred dips were taken with a standard dipper of $450 \mathrm{ml}$. This routine was continued until all adults had emerged, or until the pool was dry. The number of larvae of each instar and pupae from each dip was recorded, and pupal sexes were determined. The individuals were sampled without replacement.

Daily air temperature data were provided by the Faculty of Astronomic and Geophysical Sciences of the National University of La Plata, whose meteorological station is situated approximately $20 \mathrm{~km}$ from the study site.

Estimation of accumulative larval development time was calculated from the percentage of larvae by instar $(i)$ on each sampling day. These percentages were calculated and plotted against time on $\log \mathrm{x}$ probability paper, in order to estimate time $\left(\mathrm{t}_{50}\right)$ at which $50 \%$ of the larvae reach each successive instar (Enfield \& Pritchard 1977). Instar durations $(i d)$ in days were calculated by subtracting $t_{50(i)}$ values from $t_{50(i+1)}$. Estimation of corrected density for each instar $\left(d c_{i}\right)$ was calculated by multiplying the number of individuals sampled by the instar duration. Plotting the corrected density against larval and pupal age in days, vertical stage-specific frequency distributions were obtained and histograms were constructed. Survivorship curves were drawn connecting the midpoints of each histogram block by a straight line (Reisen et al. 1982). The number of individuals entering in each instar $\left(S_{i}\right)$ was estimated from the graph, and the stage-specific survivorship was calculated using procedures described by Service (1973, 1977a,b). Life tables were constructed following procedures used by Southwood (1966).

Parasitism caused by S. spiculatus - All larval instars were examined alive on a micro concavity slide for $S$. spiculatus parasites, at 100 magnification. For samples with less than 100 individuals, all were examined, for larger samples, a sub-sample of 100 larvae was randomly taken. Larvae parasitized with visible parasites in the body cavity were reared until parasite emergence. Unparasitized larvae were reared and checked every two days for potentially undetected parasites. Upon emergence from larvae, the post-parasite juvenile nematodes were counted.

In the fall cohorts, pupae from samples were weighed to an accuracy of $0.01 \mathrm{mg}$ and kept in individual containers until the adult molt. Males and females were dissected for parasites, and wing length was measured (accuracy of $0.01 \mathrm{~mm}$ ) from the alular notch to the distal margin excluding the fringe scales (Bock \& Milby 1981). Because the proportion of the adult mosquitoes parasitized by mermithids in nature is low, an additional sample of pupae from 100 dippers was taken every day from the first record until the day when no pupae were observed.

Nematode parasitism was measured by the prevalence (number of parasitized hosts/number of examined hosts) $x 100$, mean intensity (number of parasites/number of parasitized hosts), and abundance (number of parasites/number of examined hosts) (Morales \& Arelis Pino 1987).

Other pathogens, such as Microsporidia (Protozoa) were observed in Oc. albifasciatus, but no attempts were made to isolate and record their prevalences.

\section{RESULTS}

Larval developmental time and sexes - Abundance of Oc. albifasciatus increased from spring to fall by 2.8 times (mean \pm standard deviation $(\mathrm{SD})$ : spring $=629.3 \pm 633$, fall $=1,792.5 \pm 14.85)$; however, the population increase did not follow a linear function $(\mathrm{P}>0.05)$.

Development time from first instar to adult in pools was $9.2 \pm 1.30$ days in spring; 6 in summer, and $16.4 \pm 7.79$ in fall. Duration of the first instar was short and homogeneous during all samples; the last fall cohort however, was shown to be half the time of the other cohorts. On the other hand, the second instar was twice as long in fall, with respect to the spring and summer cohorts. The third instar duration was the most heterogeneous and no seasonal pattern was detected. The fourth instar duration was the longest with bimodal peaks at the start of spring and at fall. Pupal stage duration ranged from 1.4 days in summer to 10.3 days in fall (Table I). However, KruskalWallis ANOVA for pre-adult development times was not significantly different between cohorts $(\mathrm{H}=5.26$, df $5, \mathrm{P}=$ 0.38 ). Contingency table of sex ratios (male/female) showed significant differences between seasons $\left(\chi^{2}=7.77\right.$, df $2, \mathrm{P}$ $<0.05)$, females predominating in all cohorts except during summer (Table II).

During sampling of the cohorts, daily mean air temperature varied from $23^{\circ} \mathrm{C}$ in summer to $12^{\circ} \mathrm{C}$ at the end of fall (Fig. 1). Developmental time decreased progressively as temperature increased for subsequent cohorts in spring. The shortest developmental time occurred in the summer 
cohort (6 days) while during the fall it increased again, recording the longest developmental time in the early fall cohort (21.9 days). However, the mean developmental time of each cohort was not significantly correlated with temperature $\left(\mathrm{r}_{\mathrm{t}^{\circ} \max .}=-0.64, \mathrm{P}=0.17 ; \mathrm{r}_{\mathrm{t}^{\circ} \min .}=-0.60, \mathrm{P}=0.21\right.$; $r_{t^{\circ} \text { mean }}=-0.45, P=0.37 n=6$ ), indicating that temperature per se is not the major determinant of the developmental time of immature Oc. albifasciatus in nature.
Horizontal stage-specific life tables and life expectancies - Percent survivorship of Oc. albifasciatus from first instars to adulthood was estimated as $1.4 \%$ in spring, $2 \%$ in summer, and $0.2-4.4 \%$ in fall. In cohort 1 (spring), no survival was recorded. Fifty percent of the deaths occurred in every cohort in later instars and pupae. The highest relative proportion dying $\left(P_{i}\right)$ and daily proportion dying $\left(P d_{i}\right)$ occurred in pupal stage in all cohorts

TABLE I

Estimated development time of larvae, instar duration, and corrected density of Ochlerotatus albifasciatus

\begin{tabular}{|c|c|c|c|c|}
\hline $\begin{array}{l}\text { Instars } \\
(i) \\
\end{array}$ & $\begin{array}{l}\text { No. of individuals } \\
\left(n_{i}\right)\end{array}$ & $\begin{array}{l}\text { Larval development } \\
\text { times }\left(t_{50}\right)\end{array}$ & $\begin{array}{l}\text { Instars duration } \\
\text { in days }\left(t_{i}\right)\end{array}$ & $\begin{array}{l}\text { Corrected density } \\
\qquad\left(d c_{i}\right)\end{array}$ \\
\hline \multicolumn{5}{|c|}{ Cohort 1 (spring) } \\
\hline I & 94 & 0.9 & 0.9 & 104.4 \\
\hline II & 131 & 2.4 & 1.5 & 87.3 \\
\hline III & 177 & 4.5 & 2.1 & 84.3 \\
\hline IV & 183 & 6.8 & 2.3 & 79.6 \\
\hline \multirow[t]{2}{*}{ Pupa } & 4 & 10 & 3.2 & 1.2 \\
\hline & $n_{T}: 589$ & & & $\begin{array}{rr}d c_{T}: & 356.8 \\
d_{D}: & 0.54\end{array}$ \\
\hline \multicolumn{5}{|c|}{ Cohort 2 (spring) } \\
\hline I & 519 & 0.9 & 0.9 & 576.7 \\
\hline II & 392 & 1.9 & 1 & 392 \\
\hline III & 325 & 3.8 & 1.9 & 171 \\
\hline IV & 315 & 5.7 & 1.9 & 165.8 \\
\hline \multirow[t]{2}{*}{ Pupa } & 201 & 9.9 & 4.2 & 47.9 \\
\hline & $n_{T}: 1752$ & & & $\begin{array}{rr}d c_{T}: & 1353.4 \\
d_{D}: & 1.59\end{array}$ \\
\hline \multicolumn{5}{|c|}{ Cohort 3 (spring) } \\
\hline I & 12 & 0.9 & 0.9 & 13.3 \\
\hline II & 54 & 1.9 & 1 & 54 \\
\hline III & 41 & 3.8 & 1.9 & 21.6 \\
\hline IV & 99 & 4.9 & 1.1 & 90 \\
\hline \multirow[t]{2}{*}{ Pupa } & 1 & 7.7 & 2.8 & 0.4 \\
\hline & $n_{T}: 207$ & & & $\begin{array}{rr}d c_{T}: & 179.3 \\
d_{D}: & 0.30\end{array}$ \\
\hline \multicolumn{5}{|c|}{ Cohort 4 (summer) } \\
\hline I & 393 & 0.9 & 0.9 & 436.7 \\
\hline II & 143 & 2.2 & 1.3 & $110^{a}$ \\
\hline III & 239 & 3 & 0.8 & 298.7 \\
\hline IV & 211 & 4.6 & 1.6 & 131.9 \\
\hline \multirow[t]{2}{*}{ Pupa } & 33 & 6 & 1.4 & 23.6 \\
\hline & $n_{T}: 1019$ & & & $\begin{array}{rr}d c_{T}: & 1000.9 \\
d_{D}: & 1.46\end{array}$ \\
\hline \multicolumn{5}{|c|}{ Cohort 5 (fall) } \\
\hline I & 457 & 0.8 & 0.8 & 571.2 \\
\hline II & 1726 & 3.8 & 3 & $575.3^{b}$ \\
\hline III & 1446 & 7.5 & 3.7 & 390.8 \\
\hline IV & 1090 & 11.6 & 4.1 & 265.8 \\
\hline \multirow[t]{2}{*}{ Pupa } & 8 & 21.9 & 10.3 & 0.8 \\
\hline & $n_{T}: 4727$ & & & $\begin{array}{rr}d c_{T}: & 1803.9 \\
d_{D}: & 2.06\end{array}$ \\
\hline \multicolumn{5}{|c|}{ Cohort 6 (fall) } \\
\hline I & 364 & 0.4 & 0.4 & 910 \\
\hline II & 145 & 3.6 & 3.2 & 45.3 \\
\hline III & 430 & 4.5 & 0.9 & 477.8 \\
\hline IV & 671 & 7 & 2.3 & 291.7 \\
\hline \multirow[t]{3}{*}{ Pupa } & 237 & 10.9 & 4.1 & 57.8 \\
\hline & $n_{T}: 1847$ & & & $d c_{T}: 1782.6$ \\
\hline & & & & $d_{D}: \quad 1.94$ \\
\hline
\end{tabular}

$n_{T}$ : no. of total individuals; $d_{D}$ : mean density by dip; $a$ : we assumed II = III; $b$ : II = I, and estimated mortality equal 0 
TABLE II

Numbers of pupae from the cohorts of Ochlerotatus albifasciatus caught in spring, summer and fall, at Pereyra Park, Buenos Aires Province

\begin{tabular}{lrcl}
\hline Cohort & Male pupa & Female pupa & Sex ratio G/E \\
\hline 1 (spring) & 2 & 2 & 1 \\
2 (spring) & 80 & 121 & 0.7 \\
3 (spring) & 0 & 1 & 0 \\
4 (summer) & 17 & 10 & 1.7 \\
5 (fall) & 3 & 5 & 0.6 \\
(fall) & 118 & 119 & 0.9 \\
\hline
\end{tabular}

(Table III). Comparing mortality by larval instar, relative and daily death was heterogeneous and differed between cohorts. The highest $P_{i}$, occurred in fourth instar in all cohorts except in cohort 2 (spring), where the third instar was the most susceptible. In contrast, the value of $P d_{i}$ during the cohorts of spring was higher in early instars (Table III). The K value ["Killing power" of Varley \& Gradwell (1960)] was higher in cohort 5 (fall) than in the other cohorts (Table III). Using survivorship curves (Fig. 2), a series of life tables was calculated using 1-day time increments. Survival curves analyzed by Wilcoxon and Log-rank tests show homogeneity between all cohorts $\left(\chi^{2}=8.00, \mathrm{df}=4, \mathrm{P}=0.092\right)$. The expectation of life $\left(e_{x}\right)$ progressively decreased from the early larvae until molting to pupa, except for the cohort 2 (spring) which showed an increment of $e_{x}$ at the third day (Fig. 3), when larvae molt to third instar. The pupal stage showed similar tendencies as the larval stages, except for cohort 5 (fall) where an increment of $e_{x}$ was observed when more than $50 \%$ of larvae reached the pupal stage (Figs 2,3). Life expectancy distributions between cohorts did not differ significantly when tested by a Kolmogorov-Smirnov 2-sample test (Cohort $1 /$ cohort $2: \mathrm{D}_{\max }=0.35, \mathrm{n}_{1}=9, \mathrm{n}_{2}=11$; cohort $1 /$ cohort $4: \mathrm{D}_{\max }=0.44, \mathrm{n}_{4}=7$; cohort $2 /$ cohort $4: \mathrm{D}_{\max }=$
0.53; cohort 5/cohort 6: $\mathrm{D}_{\max }=0.40, \mathrm{n}_{5}=21, \mathrm{n}_{6}=12$; cohort 4/cohort 6: $\mathrm{D}_{\max }=0.54 ; \mathrm{P}>0.1$. Cohort 4/cohort 6: $\left.\mathrm{D}_{\text {max }}=0.57, \mathrm{P}>0.05\right)$.

Seasonal parasitism - S. spiculatus was present in all cohorts of Oc. albifasciatus, except for cohort 1 (spring) in which no parasitism occurred. Because the number of parasitized hosts was not recorded for spring and summer cohorts, parasite abundance was used as an index of parasitism. Abundance ranged from 0.09 to 0.52 in all cohorts except for cohort 5 (fall), where abundance was higher (range: 1.56-2.41). To compare seasonal abundance variability of $S$. spiculatus in Oc. albifasciatus larvae, we tested all cohorts by Kruskal-Wallis Anova on ranks and significant differences were observed $(\mathrm{H}=41.50$, df $4, \mathrm{P}<0.001)$. Multiple comparison by Dunn's test showed significant differences between cohort 5 (fall) and the other cohorts $(\mathrm{P}<0.05)$.

To determine whether the abundance varied between ages of the hosts, early instars (I + II) were compared with late instars (III + IV) from all cohorts and seasons. The abundance was higher in later instars in all cohorts, although this difference was statistically significant only for cohort 5 (Table IV).

Comparative occurrence of Oc. albifasciatus parasitized by S. spiculatus, during the fall - S. spiculatus can occur in high and low levels of parasitism. Individuals of cohort 5 (high parasitism) and 6 (low parasitism) were compared for effects of parasite infesty.

In both cohorts, simple and multiple parasitism were recorded in all stages of the host. Prevalence of the nematode in Oc. albifasciatus in cohort 5 was $86.9 \%$, and ranged from $33.3 \%$ in pupae to $96.2 \%$ in third instar. In cohort 6 , prevalence was $14.6 \%$, ranging from $4.3 \%$ in first instar to $24 \%$ in second instar (Fig. 4). The mean intensity of parasitism in Oc. albifasciatus during development of cohort 5 was significantly higher than during cohort 6 for all immature stages (Mann-Whitney rank sum test: $\mathrm{T}=39.50$, $\mathrm{n}=5, \mathrm{P}=0.008)$. Distribution of instars did not differ

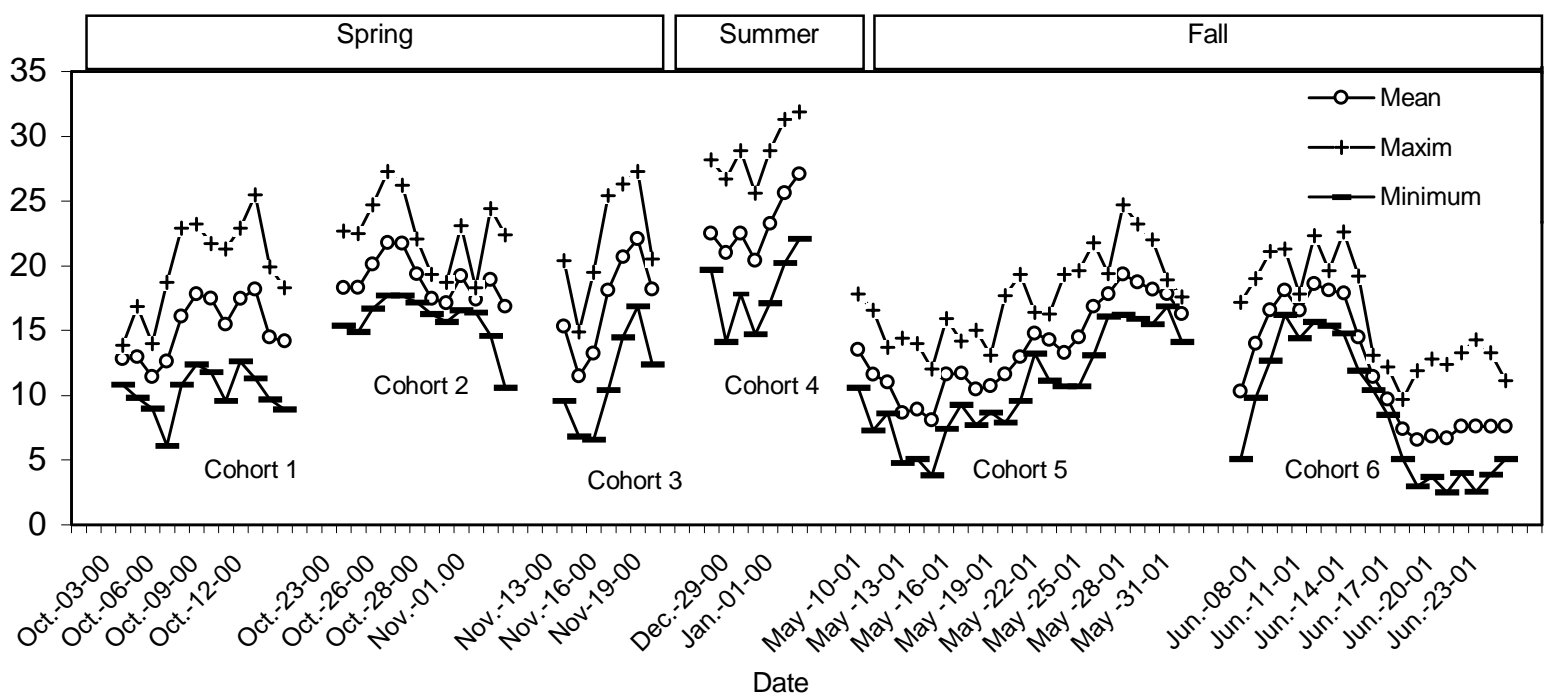

Fig. 1: temperature $\left({ }^{\circ} \mathrm{C}\right)$ occurring during the development of the six cohorts 
between both cohorts (Kolmogorov-Smirnov 2-sample test, $\left.\mathrm{D}_{\max }=0.36, \mathrm{P}>0.1, \mathrm{n}=5\right)$.

At both levels of parasitism, parasite numbers were recorded in adult mosquitoes. These adults arose only from third and fourth instar larvae collected from the field; no parasitized first and second instars larvae survived to the adult stage. However the percentage of parasitized larvae of $O c$. albifasciatus molting to adults was less than $2 \%$ in both cohorts (Table V).

In adult Oc. albifasciatus, larval parasites were located in the abdomen of mosquitoes, but when multiple parasitism occurred, nematodes invaded the thorax as well. The proportion of Oc. albifasciatus adults parasitized by S. spiculatus during the cohort 5 was $14.2 \%$, and $5.7 \%$ in the cohort 6 . In both cohorts, parasitized males $(61.9 \%$ and $6.3 \%$ respectively) were not significantly different from parasitized female ( $38.1 \%$ and $4.8 \%$ respectively) (Cohort 5: $\mathrm{G}_{\mathrm{adj}}=1.02 ;$ Cohort 6: $\mathrm{G}_{\mathrm{adj}}=0.68 ; \mathrm{P}>0.1$ ). To establish if parasitism affects the weight of pupa and size of adult $O$. albifasciatus mean values were compared by sex. Size and weight of parasitized individuals did not differ significantly from unparasitized (Table VI). Coefficients of variation of wing-lengths were $4.4 \%$ for males, and $5.8 \%$ for females. However, when comparing parasitized and unparasitized sexes, parasitized females (Table VI) was the most heterogeneous group.

Because multiple parasitism occurred in both male and female adults, the number of parasites per mosquito was

TABLE III

Stage-specific mortalities of Ochlerotatus albifasciatus at Pereyra Park, Buenos Aires Province

\begin{tabular}{lccccc}
\hline Age in days at & & & & & \\
Stage & beginning of & No. entering stage & Deaths in stage & Relative proportion & Proportion dying \\
$(i)$ & stage $\left(t_{i}\right)$ & $\left(S_{i}\right)$ & $\left(D_{i}\right)$ & dying $\left(P_{i}\right)$ & daily $\left(P d_{i}\right)$
\end{tabular}

\begin{tabular}{lc}
\hline Cohort 1 (spring) & \\
I & 0 \\
II & 0.9 \\
III & 2.4 \\
IV & 4.5 \\
Pupa & 6.8 \\
Adult & 10
\end{tabular}

120

$\begin{array}{rl} & \\ 24 & 0.200 \\ 11 & 0.115 \\ 5 & 0.059 \\ 36 & 0.450 \\ 44 & 1.000\end{array}$

\section{S 0.000}

$\begin{array}{ll}\text { Cohort 2 (spring) } & \\ \text { I } & 0 \\ \text { II } & 0.9 \\ \text { III } & 1.9 \\ \text { IV } & 3,8 \\ \text { Pupa } & 5.7 \\ \text { Adult } & 9.9\end{array}$

Cohort 4 (summer)

$\begin{array}{ll}\text { I } & 0 \\ \text { II } & 0.9 \\ \text { III } & 2.2 \\ \text { IV } & 3 \\ \text { Pupa } & 4.6 \\ \text { Adult } & 6\end{array}$

Cohort 5 (fall)

I
II
III
IV
Pupa
Adult

$\begin{array}{rr}0 & 575 \\ 0.8 & 575 \\ 3.8 & 485 \\ 7.5 & 320 \\ 11.6 & 185 \\ 21.9 & 0\end{array}$

S 0.002

$\begin{array}{lc}\text { Cohort 6 (fall) } & \\ \text { I + II } & 0 \\ \text { III } & 3.6 \\ \text { IV } & 4.5 \\ \text { Pupa } & 7 \\ \text { Adult } & 10.9\end{array}$

10
S 0.020

$\begin{array}{rrr}690 & 210 & 0.304 \\ 480 & 170 & 0.354 \\ 310 & 140 & 0.452 \\ 170 & 45 & 0.265 \\ 125 & 115 & 0.920 \\ 10 & & \end{array}$

S 0.014

0.265
0.203
0.164
0.680
0.875

0.289

0.160

0.200

0.509

0.774

K 0.436

0.332
0.354
0.271
0.149
0.452

0.158

0.190

0.261

0.133

1.097

K 1.839

0.134

0.098

0.078

0.495

0.903

K 1.708

0.000
0.157
0.340
0.422
0.995

0.000

0.055

0.106

0.125

0.402

0

0.074

0.181

0.238

2.267

K 2.760

0.207
0.124
0.296
0.730

0.379

0.248

0.494

0.814

0.138

0.271

0.256

0.336

K 1.357

S: instars to adulthood survivorship (adult/instars I); K: sum of "killing power" (k) 
compared in both cohorts. In the cohort 5, parasites per adult mosquito ranged from 1 to $7(2.4 \pm 1.46)$ in males, and from 1 to $6(2.1 \pm 1.56)$ in females. On the other hand in cohort 6 it ranged from 1 to $3(1.8 \pm 0.79)$ in males, and from 1 to $2(1.3 \pm 0.52)$ in females. However, no significant differences between groups were detected (Kruskal-Wallis Anova, $\mathrm{H}=4.233$, $\mathrm{df}=3, \mathrm{P}=0.237$ ).

\section{DISCUSSION}

Fava et al. (2001) reported that the developmental time of first, second and third instars, and pupa of $O c$. albifasciatus in semi-natural conditions decreased as temperature increased. In contrast, the current study described no remarkable variation in developmental time among these instars. However, large variation occurred in fourth
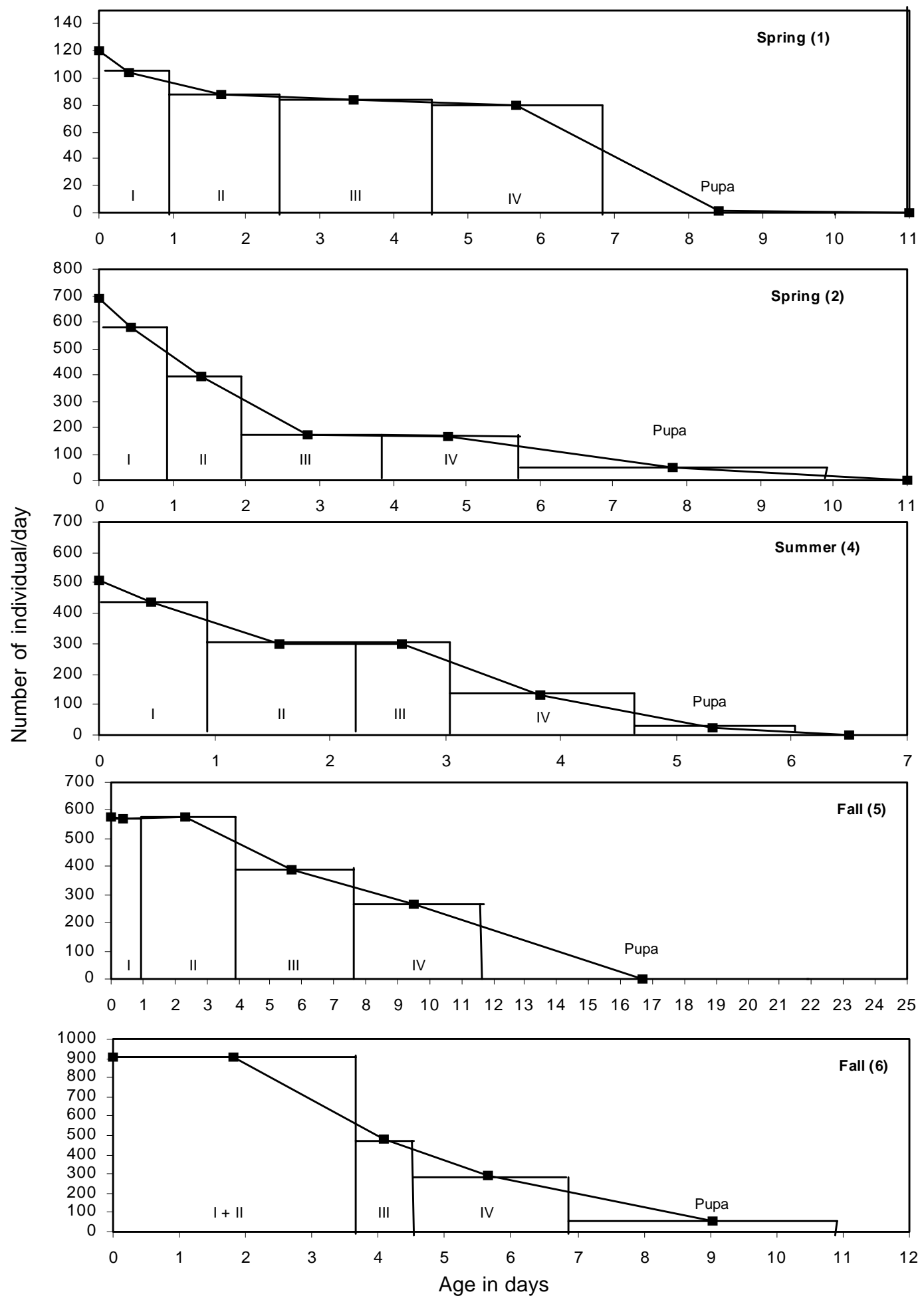

Fig. 2: stage-specific age distribution and survivorship curves for immature stages of Ochlerotatus albifasciatus 
instar and pupal stage where developmental time increased when environmental temperature was low (cohorts of fall and early spring).

With respect to total immature development times, no significant differences were seen between cohorts from spring to fall. Fava et al. (2001), studying three groups of cohorts (two winter one spring), detected significant dif- ferences in development time between the first group from winter and the remaining groups. Fontanarrosa et al. (2000), in a study developed under natural conditions, reported $O c$. albifasciatus development time ranging from 6 days to 32 days, associated with mean temperature $\left(24^{\circ} \mathrm{C}\right.$ and $13^{\circ} \mathrm{C}$ respectively); however, these authors did not detect significant differences in the development time.

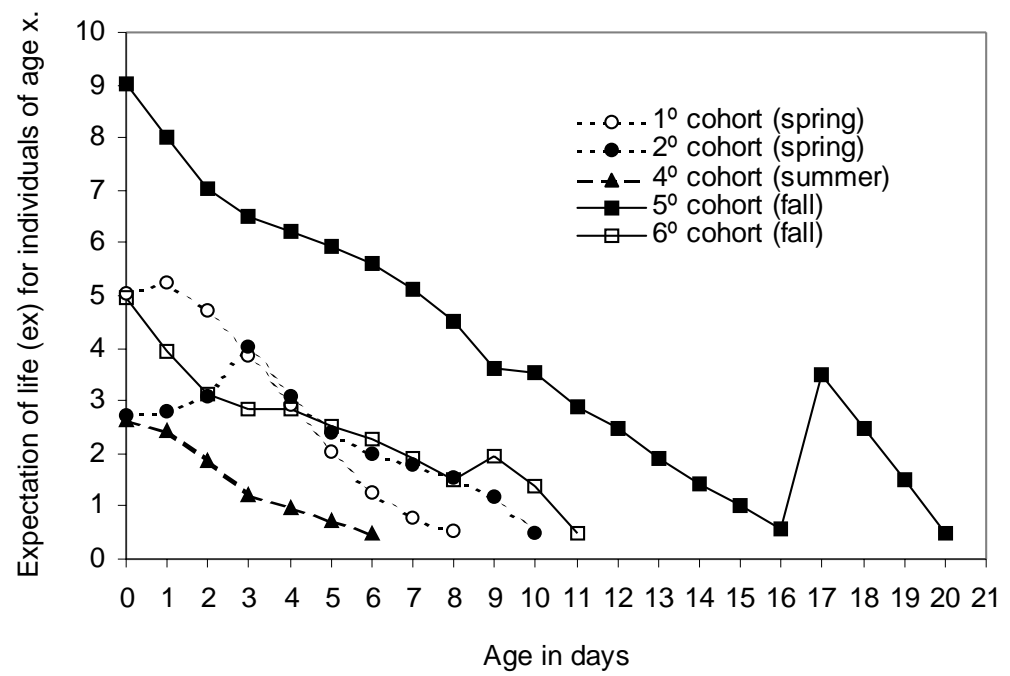

Fig. 3: expectation of life $\left(e_{x}\right)$ plotted as a function of age in days for Ochlerotatus albifasciatus

TABLE IV

Mean \pm standard deviation of the abundance of Strelkovimermis spiculatus in Ochlerotatus albifasciatus larvae, and Student $t$ test

\begin{tabular}{lccccc}
\hline & \multicolumn{5}{c}{ Cohort } \\
\cline { 2 - 6 } Instar & Spring 2 & Spring 3 & Summer 4 & Fall 5 & Fall 6 \\
\hline I-II & $9.67 \pm 13.43$ & $24.33 \pm 37.07$ & $7.67 \pm 9.29$ & $156.38 \pm 105.79$ & $16.25 \pm 26.06$ \\
III-IV & $52.50 \pm 54.65$ & $34.50 \pm 16.18$ & $23.33 \pm 5.51$ & $240.68 \pm 116.49$ & $30.22 \pm 37.03$ \\
Student test & -1.301 & -0.501 & -2.512 & -2.138 & -0.676 \\
t & 0.225 & 0.638 & 0.066 & $0.040^{a}$ & 0.513 \\
P & 9 & 5 & 4 & 33 & 11 \\
d.f & & & & & \\
\hline
\end{tabular}

$a$ : statistically significant

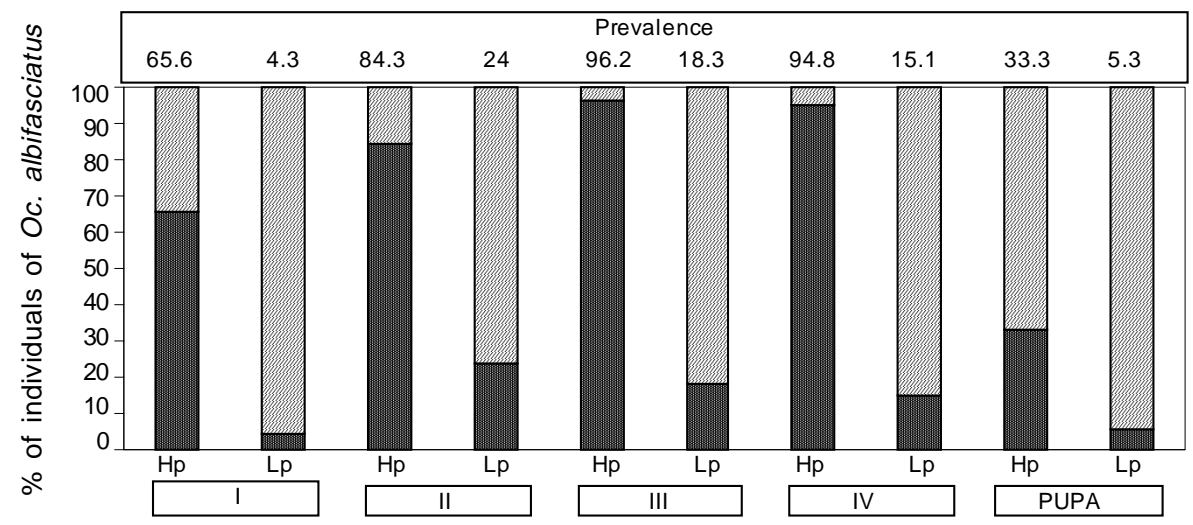

Stages

Fig. 4: prevalence and stage-specific age distribution of Ochlerotatus albifasciatus parasitized (black bar), and unparasitized (grey bar) in the cohorts 5 and 6 . Hp: cohort (5) with high parasitism, Lp: cohort (6) with low parasitism 
TABLE V

Percent of immature Ochlerotatus albifasciatus parasitized, molting to adult

\begin{tabular}{lccrcc}
\hline & \multicolumn{2}{c}{ Cohort 5} & & \multicolumn{2}{c}{ Cohort 6 } \\
\cline { 2 - 3 } \cline { 5 - 6 } Stages & $\begin{array}{c}\text { No. of individuals } \\
\text { parasitized }\end{array}$ & $\begin{array}{c}\text { \% of individuals } \\
\text { molting to adult }\end{array}$ & & $\begin{array}{c}\text { No. of individuals } \\
\text { parasitized }\end{array}$ & $\begin{array}{c}\text { \% of individuals } \\
\text { molting to adult }\end{array}$ \\
\hline I & 299 & 0 & 8 & 0 \\
II & 472 & 0 & 29 & 0 \\
III & 536 & 0.19 & 30 & 0 \\
IV & 766 & 1.57 & 56 & 1.78 \\
Pupa & 3 & 100 & 13 & 100 \\
\hline
\end{tabular}

TABLE VI

Mean wet weight and wing size ( \pm SD) of pupa and adult of Ochlerotatus albifasciatus parasitized and unparasitized by Strelkovimermis spiculatus, and test results. The values were taken from fall cohort samples and from additional 100 samples of the same pools

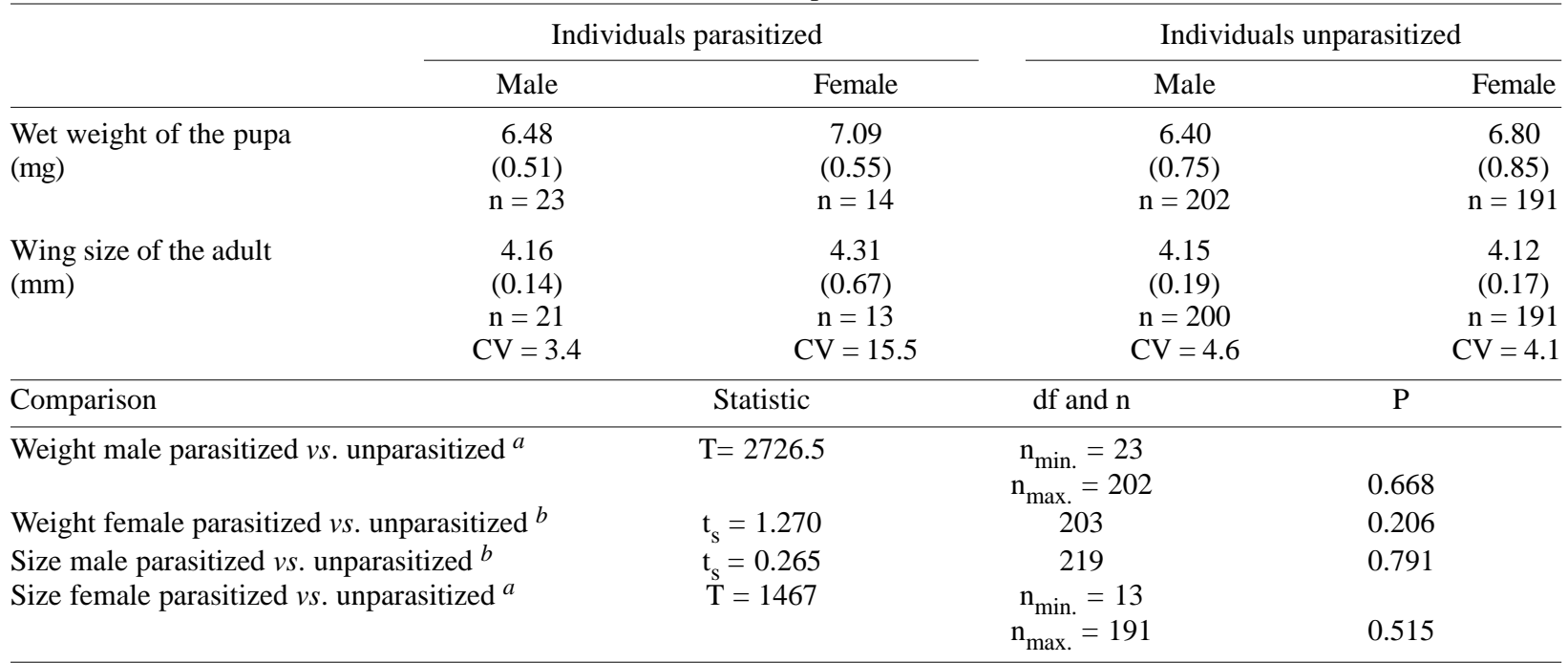

$\bar{a}$ : Mann-Witney rank sum test because the data were not normal (Kolmogorov-Smirnov test for normality, $\mathrm{P}<0.001) ; b$ : Student $\mathrm{t}$ test; CV: coefficient of variation

All these studies indicate temperature as the major influence on development time of immature Oc. albifasciatus. However, significant differences were observed only in the winter, when lowest temperatures occurred.

Although Fontanarrosa et al. (2000) attributed this heterogeneity in the development time to seasonal temperature, the variation occurring in each cohort in a particular season is probably a consequence of other factors. Growth, development and survivorship of immature mosquitoes are affected by population density (e.g. Léonard \& Juliano 1995, Gleiser et al. 2000) and by the presence of enemies (Nannini \& Juliano 1997). Our results show how development of Oc. albifasciatus changes during two successive cohorts in fall. Development time of immatures in the second cohort was shorter than in the first, despite the lower temperature. Possibly, the high density of the host (which moreover favored the parasitism by S. spiculatus) may have slowed development time in cohort 5. In contrast, the cohort 6 experienced lower density and parasitism, and the developmental period was faster.
A survival curve constructed for Oc. albifasciatus was described as type II (Ludueña Almeida \& Gorla 1995) with the risk of death approximately constant with age (Slobodkin 1962). In contrast, our life table in nature revealed low mortality in young instars, and higher in old instars as in an intermediate stage between Type III and I curves of mortality of Slobodkin (1962).

First instar/adult survivorship values for $O c$. albifasciatus ranged from $0 \%$ to $4.4 \%$. However, comparisons with previously published $O c$. albifasciatus survival may be misleading because those studies did not include all immature stages. Averages for other field populations of mosquitoes, such Aedes cantans (Meigen) and Aedes africanus (Theobald) reported survivorship values of $6.2 \%$ and $9-17 \%$ (Service 1973, Lakhani \& Service 1974) substantially higher than in our results.

Fava et al. (2001) attributed the mortality in young immature of Oc. albifasciatus to temperature variation. Because their experiments were made in a $500 \mathrm{ml}$ flask, neither presence of natural enemies nor other natural causes of mortality were reported. Our results showed 
that the lowest " $\mathrm{K}$ " value $(0.44)$ occurred in cohort 1 from early spring, coincident with the absence of $S$. spiculatus in the pool. In contrast, the highest " $\mathrm{K}$ " value (2.76) occurred in cohort 5 from fall, when the highest parasitism was recorded. In remaining cohorts although parasitism occurred, "K" values were lower and homogeneous. These results indicated $S$. spiculatus to be a remarkable natural enemy of the $O c$. albifasciatus immature stages.

Although multiple parasitism occurred in all instars, the main mortality was recorded at the end of fourth larval instar (Table III). Low mortality in early instars may be a consequence of high tolerance of Oc. albifasciatus to the parasite. In contrast to Camino (1988) who reported that multiple parasitism kill first and second instars, we believe that a high proportion of multi-parasitized young larvae does not exactly kill this instars in nature. This assumption is supported by our data for abundance of $S$. spiculatus parasitizing Oc. albifasciatus, that show an increment in the later instars (Table IV).

Parasitism by S. spiculatus - The majority of surveys of S. spiculatus in Oc. albifasciatus were performed with a weekly or irregular design of sampling, and have reported prevalence of $80 \%$ (Maciá et al. 1995) and from 0\% to $100 \%$ (Micieli \& García 1999). Because the development time of Oc. albifasciatus is short, and the permanence of the larva in fourth instar is longer than in younger instars, the prevalence may be biased as a consequence of sampling frequency.

During the spring Maciá et al. (1995) and Micieli and García (2000) reported 12 and $67 \%$ of parasitism respectively, in third and fourth instar larvae. In the present study, no parasitism was recorded in the first spring cohort; however, in the later cohort, $S$. spiculatus was present in all instars with abundances ranging between $9 \%$ in first and second instars to $52 \%$ in third and fourth instars.

Both earlier reports indicated an absence of hatching of Oc. albifasciatus in summer (December to February). In contrast, we recorded a cohort rearing from the end of December to January with parasitism by $S$. spiculatus similar to spring and fall prevalence (except for cohort 5).

Comparative occurrence of parasitism - Although parasitism by $S$. spiculatus is known for five mosquito species in nature (Campos et al. 1993, García et al. 1994, Maciá et al. 1995), epizootic peaks were recorded only for Oc. albifasciatus (Maciá et al. 1995, Micieli \& García 1999). Parasitism in Oc. albifasciatus occurred during all seasons, with peaks restricted to spring and fall (Maciá et al. 1995, Micieli \& García 1999). Even though the causes of this increase are unknown, certainly they are closely related to the high density of Oc. albifasciatus immatures.

During the fall, we recorded two cohorts of $O c$. albifasciatus parasitized by the mermithid. In cohort 6 , penetration by the pre-parasite occurred mainly during the first instar of the host, and was reflected by the highest prevalence recorded in the second instar. Then prevalence progressively decreased, possibly as a consequence of the absence of pre-parasites; the mortality due to parasite emergence and, consequently, the proportional increase in the amount of remaining unparasitized larvae. However, in cohort 5, prevalence increased from first to third instar, possibly as a consequence of nematode hatches after a second rainfall.

Parasitic abundance was not significantly different between early and late instars in cohort 6. By contrast, the abundance was twice as high in late rather than early instar larvae during cohort 5. From high multiple parasitisms detected in fourth instar in cohort 5, the probability of this larvae surviving to adults was expected to be lower than cohort 6 , with its low multiple parasitism. Surprisingly, $35.1 \%$ of parasitized fourth instar larvae pupated in both cohorts. This suggested that the proportion of parasitized adults emerging independs on the abundance of larval parasitism.

The abundance of parasites in third and fourth instar Oc. albifasciatus was explained by the presence of infective parasites in the pools (at least for 13 days at the time when larvae molted to third instar), or as consequence of new hatchings of $S$. spiculatus. Both hypotheses may be possible because during the development of cohort 5 , rainfall on the 8th day, increased the surface area of the pool. Micieli and García (1999) made similar observations. They collected pre-parasites of $S$. spiculatus from a pool for 13 days, and reported that six days later, another rain occurred and new pre-parasites were found. These observations disagree with the survivorship of $48 \mathrm{~h}$ estimated for the pre-parasites by Camino and Reboredo (1994).

Parasitism occurred in adult mosquito - The only record of $S$. spiculatus parasitizing adults mosquito in nature was reported by García et al. (1994), who isolated a worm from a $C x$. dolosus Lynch Arribálzaga female caught by CDC trap. Here we reported both sexes of adult $O c$. albifasciatus parasitized by $S$. spiculatus, collected as third and fourth instar, and pupa from both cohort 5 (high parasitism) and 6 (low parasitism). Furthermore, parasitism occurring in first and second instars larvae culminated with the emergence of the nematode from late fourth instar Oc. albifasciatus.

As a result of the late parasitism occurred in previously parasitized larvae, parasites were observed in asynchronous development in some third and fourth instar Oc. albifasciatus. In these cases the emergence of the first nematode killed the host. However, when later parasitism occurred in third and fourth instar not previously parasitized, these nematodes were observed in the adult mosquito.

Larger individuals of mosquito have a greater tendency to disperse from the larval habitat (Nasci 1987) and hence may have greater potential to disperse $S$. spiculatus to new pools. Therefore the wing lengths of the of $O c$. albifasciatus adults were compared to see if parasitized mosquitoes differed in size from unparasitized ones. No difference was detected between mean adult size of parasitized and unparasitized Oc. albifasciatus, even though multiple parasitism occurred. Apparently, parasitized adults have the same capacity of dispersion as and unparasitized ones and can carry $S$. spiculatus to others pools.

\section{ACKNOWLEDGMENTS}

To Drs A Maciá (Facultad de Ciencias Naturales y Museo de La Plata, Universidad Nacional de La Plata, Argentina), and 
LP Lounibos (Florida Medical Entomology Laboratory, University of Florida, USA) for critical review.

\section{REFERENCES}

Andis MD, Meek CL 1985. Mortality and survival patterns for the immature stages of Psorophora columbiae. J Am Mosq Control Assoc 1: 357-362.

Bock ME, Milby MM 1981. Seasonal variation of wing length and egg raft size in Culex tarsalis. Proc Calif Mosq Vector Control Assoc 49: 64-66.

Cabrera AL, Willink A 1980. Biogeografía de América Latina. Serie de Biología, Monografía 13, The General Secretariat of the Organization of America States, Washington, 122 pp.

Camino NB 1988. Efecto del parasitismo múltiple en la determinación del sexo de Strelkovimermis spiculatus Poinar y Camino, 1986 (Nematoda, Mermithidae) en larvas de Culex pipiens fatigans Wiedemann, 1828. Ierhingia Sér Misc 2: 93-97.

Camino NB, Reboredo GR 1994. Biología de Strelkovimermis spiculatus Poinar y Camino, 1986 (Nematoda: Mermithidae) parásito de mosquitos (Diptera: Culicidae) en condiciones de laboratorio. Neotrópica 40: 45-48.

Camino NB, Reboredo GR 1996. Producción de Strelkovimermis spiculatus Poinar y Camino, 1986 (Nematoda: Mermithidae). Neotrópica 42: 47-50.

Campos RE, Maciá A, García JJ 1993. Fluctuación estacional de culícidos (Diptera) y sus enemigos naturales en zonas urbanas de los alrededores de La Plata, provincia de Buenos Aires. Neotrópica 39: 55-66.

Darsie RF, Mitchell CF 1985. The mosquitoes of Argentina: Parts I and II. Mosq Syst 17: 153-360.

Docena GH, Benítez P, Campos RE, Maciá A, Fernández R, Fossati CA 1999. Detection of allergens in Aedes albifasciatus mosquito (Diptera: Culicidae) extracts by immunological methods. Invest Allergol Clin Immunol 9: 165-171.

Enfield MA, Pritchard G 1977. Estimates of population size and survival of immature stages of four species of Aedes (Diptera: Culicidae) in a temporary pond. Can Ent 109: 1425-1434.

Fava FD, Ludueña Almeida FF, Almirón WR, Brewer M 2001. Winter biology of Aedes albifasciatus (Diptera: Culicidae) from Córdoba, Argentina. J Med Entomol 38: 253-259.

Fontanarrosa MS, Marinone MC, Fisher S, Orellano PW, Schweigmann N 2000. Effects of flooding and temperature on Aedes albifasciatus development time and larval density in two rain pools at Buenos Aires University City. Mem Inst Oswaldo Cruz 95: 787-793.

García JJ, Camino NB 1990. Primera cita para la Argentina de infecciones naturales en larvas de Culex pipiens (L.) (Diptera: Culicidae). Neotrópica 36: 83-86.

García JJ, Micieli MV 2000. Estacionalidad poblacional de los estados inmaduros de Aedes albifasciatus (Diptera: Culicidae) en la provincia de Buenos Aires, Argentina. Rev Biol Trop 48: 623-628.

García JJ, Campos RE, Maciá A 1994. Prospección de enemigos naturales de culicidae (Diptera) de la selva marginal de Punta Lara (Prov. de Buenos Aires, República Argentina). Rev Acad Colomb Cienc 19: 209-215.

Gleiser RM, Urrutia J, Gorla DE 2000. Body size variation of the floodwater mosquito Aedes albifasciatus in Central Argentina. Med Vet Entomol 14: 38-43.

Lakhani KH, Service MW 1974. Estimated mortalities of the immature stages of Aedes cantans (Mg.) (Diptera: Culicidae) in a natural habitat. Bull Ent Res 64: 265-276.

Léonard PM, Juliano SA 1995. Effect of leaf litter and density on fitness and population perfomance of the hole mosquito Aedes triseriatus. Ecol Entomol 20: 125-136.

Ludueña Almeida FF, Gorla DE 1995. The biology of Aedes (Ochlerotatus) albifasciatus Macquart, 1838 (Diptera: $\mathrm{Cu}-$ licidae) in Central Argentina. Mem Inst Oswaldo Cruz 90: 463-468.

Maciá A, García JJ, Campos RE 1995. Bionomía de Aedes albifasciatus y Ae. crinifer (Diptera: Culicidae) y sus enemigos naturales en Punta Lara, Buenos Aires. Neotrópica 41: 43-50.

Micieli MV, García JJ 1999. Estudios epizootiológicos de Strelkovimermis spiculatus Poinar y Camino, 1986 (Nematoda, Mermithidae) en una población natural de Aedes albifasciatus Macquart (Diptera, Culicidae) en la Argentina. Misc Zool 22: 31-37.

Mitchell CJ, Monath TP, Sabattini MS, Daffner JF, Cropp CB, Calisher CH, Darsie Jr RF, Jakob WL 1987. Arboviruse isolations from mosquitoes collected during and after the 1982-1983 epizootic of Western Equine Encephalitis in Argentina. Am J Trop Med Hyg 36: 107-113.

Morales G, Arelis Pino L 1987. Parasitología Cuantitativa, Fundación Fondo Editorial Act. Cient. Venezolana, Caracas, Venezuela, $132 \mathrm{pp}$.

Nannini MA, Juliano SA 1997. Effects of developmental asynchrony between Aedes triseriatus (Diptera: Culicidae) and its predator Toxorhynchites rutilus (Diptera: Culicidae). J Med Entomol 34: 457-460.

Nasci RS 1987. Adult body size and parity in field populations of the mosquitoes Anopheles crucians, Aedes taeniorhynchus and Aedes sollicitans. J Am Mosq Contol Assoc 3: 636-637.

Poinar Jr GO, Camino NB 1986. Strelkovimermis spiculatus $\mathrm{n}$. sp. (Mermithidae: Nematoda) parasitizing Aedes albifasciatus Macq. (Culicidae: Diptera) in Argentina. $J$ Nematol 18: 317-319.

Reisen WK, Siddiqui TF 1979. Horizontal and vertical estimates of immature survivorship for Culex tritaeniorhynchus (Diptera: Culicidae) in Pakistan. J Med Entomol 16: $207-$ 218.

Reisen WK, Azra K, Mahmood F 1982. Anopheles culicifacies (Diptera: Culicidae): horizontal and vertical estimates of immature development and survivorship in rural Punjab province, Pakistan. J Med Entomol 19: 413-422.

Service MW 1973. Mortalities of the larvae of the Anopheles gambiae Giles complex and detection of predators by the precipitin test. Bull Ent Res 62: 359-369.

Service MW 1977a. Ecological and biological studies on Aedes cantans (Meig.) (Diptera: Culicidae) in Southern England. Ann Appl Ecol 14: 159-196.

Service MW 1977b. Mortalities of the immature stages of species B of the Anopheles gambiae complex in Kenya: comparison between rice fields and temporary pools, identification of predators, and effects of insecticidal spraying. $J$ Med Entomol 13: 535-545.

Service MW 1993. Mosquito Ecology, 2nd ed., Elsevier, New York, $988 \mathrm{pp}$.

Slobodkin LB 1962. Grow and Regulation of Animal Populations, Holt, Reinehart \& Winston, New York, 184 pp.

Southwood TRE 1966. Ecological Methods, Methuen and Co., London, $389 \mathrm{pp}$.

Varley GC, Gradwell GR 1960. Key factors in population studies. J Anim Ecol 29: 481-486. 